\title{
Pulmonary diffusion impairment following heart transplantation: a prospective study
}

\author{
J.J. Egan*, L. Lowe*, N. Yonan**, A.N. Rahman**, C.A. Campbell**, \\ A.K. Deiraniya**, K.B. Carroll*, A.A. Woodcock*
}

Pulmonary diffusion impairment following heart transplantation: a prospective study. J.J. Egan, L. Lowe, N. Yonan, A.N. Rahman, C.A. Campbell, A.K. Deiraniya, K.B. Carroll, A.A. Woodcock. CERS Journals Ltd 1996.

ABSTRACT: The aim of this prospective study was to confirm whether and when a fall in gas transfer occurs following heart transplantation (HT); and to examine the potential relationship between gas transfer and haemodynamic change, immunosuppression, and cytomegalovirus (CMV) infection.

The lung physiology of 34 heart transplant recipients (HTR) and 14 control patients undergoing coronary artery bypass grafting (CABG) were studied. The absolute and standardized residual values of forced expiratory volume in one second (FEV1), forced vital capacity (FVC), residual volume (RV), forced residual volume (FRC), total lung capacity (TLC), transfer factor of the lungs for carbon monoxide $(T \mathrm{~L}, \mathrm{CO})$ and carbon monoxide transfer coefficient $(\mathrm{KCO})$ were measured before and at 30, 60, 90, 120 and 150 days after HT. These data were compared to haemodynamic status, graft rejection, cyclosporin levels and episodes of CMV infection. Lung function was studied in a group of patients before and 4 weeks after CABG.

There was a significant fall in mean $K \mathrm{CO}$ after HT (pre-HT=1.29 and post-HT= $1.06 \mathrm{mmol} \cdot \mathrm{min}^{-1} \cdot \mathrm{kPa}^{-1} \mathrm{~L}^{-1}$ ) but not after $\mathrm{CABG}$ (pre-CABG $=1.49$, post-CABG $=1.5$ mmol $\cdot \mathrm{min}^{-1} \cdot \mathrm{kPa}^{-\mathrm{L}^{-1}}$. No relationship was observed between gas transfer and CMV. At the latest stage following HT (150 days) there was a positive correlation between $T L, C O$ (absolute value and standardized residual) and mean cyclosporin level $(r=0.48$ and $r=0.44$, respectively) and also between the absolute $K \mathrm{CO}$ and actual $(r=0.56)$ and mean $(r=0.55)$ cyclosporin levels.

Following HT, there is an early fall in gas transfer, which is independent of the effects of surgery and bypass, implicating early immunosuppression (e.g. antithymocyte globulin/cyclosporin).

Eur Respir J., 1996, 9, 663-668.
*North West Lung Centre, and **Dept of Cardiothoracic Surgery, Wythenshawe Hospital, Manchester, UK.

Correspondence: J. Egan North West Lung Centre Wythenshawe Hospital Southmoor Road Manchester M23 9LT UK

Keywords: Cyclosporin heart transplant immunosuppression pulmonary diffusion impairment

Received: July 281995

Accepted after revision November 211995
A number of studies have suggested that abnormal pulmonary function, specifically a fall in pulmonary transfer factor, occurs following heart transplantation (HT). Several different hypotheses have been advanced as an explanation, including cyclosporin [1,2], persistent changes associated with pulmonary venous hypertension [3], and cytomegalovirus (CMV) infection [4]. All of these studies were retrospective without control groups.

It is possible that abnormal lung function after HT reflects the effects of sternotomy and bypass. Indeed, considerable attention has been paid to the changes in pulmonary function following routine coronary artery bypass grafting $(\mathrm{CABG})[5]$. It is recognized that bypass and the resulting red cell trauma can result in the release of inflammatory mediators, which, in turn, are implicated in the aetiology of increased lung permeability following bypass [6]. In addition, a sternotomy has detrimental effects on the mechanics of lung function both by altering the mechanics of rib movement [7], and by reducing the efficiency of the thoracic muscles [8].

Other factors may influence pulmonary function, for example, heart transplant recipients (HTR) receive rabbit antithymocyte globulin (RATG), steroids, cyclosporin and azathioprine and are, therefore, prone to routine and opportunistic infection. Preoperatively, they may have received amiodarone, and up to one third of patients awaiting transplantation are recognized as having pulmonary diffusion impairment [9], possibly resulting from chronic pulmonary congestion.

This study prospectively evaluated changes that occurred in lung function after HT in comparison to a group of patients undergoing $\mathrm{CABG}$, and investigated the relationship between changes in gas transfer following transplant and rejection, cyclosporin level, human cytomegalovirus (HCMV) infection, and pulmonary capillary wedge pressure (PCWP).

Methods and patients

\section{Patients}

All patients admitted for HT to Wythenshawe Hospital from January 2, 1992 until January 7, 1993 were enrolled 
by informed consent into this study. Ethical approval was obtained from South Manchester District Health Authority Ethics Committee. There were 38 patients ( 34 males and 4 females; mean age 48 yrs; 20 smokers) who underwent HT during this period (ischaemic heart disease $n=25$; cardiomyopathy $n=11$; valvular heart disease $n=2$ ).

Four died perioperatively (graft failure $n=3$; haemorrhage $n=1$ ) and were not enrolled into the study. Two patients underwent no pretransplant pulmonary function tests because urgent heart transplantation was undertaken but these two patients were followed longitudinally after transplantation.

Sixteen patients undergoing routine CABG for ischaemic heart disease were enrolled as control subjects (mean age 56 yrs; 14 males and 2 females; 13 ex-smokers). All had normal left ventricular function before and after surgery as assessed clinically and by transthoracic echocardiography. One patient was excluded as a result of developing a sternal wound infection and one patient defaulted, so that 14 completed the study.

Four enrolled patients died during the study period (bowel perforation 19 days; pancreatitis 57 days; Pneumocystis pneumonia 107 days; and cholecystis/sepsis 87 days post-transplantation).

\section{Lung function}

Lung function studies were performed prior to and monthly for 6 months following HT, and before and 1 month after CABG. Twelve patients who had their first post-transplant lung function test completed before or later than $30 \pm 10$ days, were not included in the comparison between transplant patients and controls.

The following parameters were measured: forced expiratory volume in one second (FEV1), forced vital capacity (FVC), residual volume (RV), functional residual capacity (FRC), (Gould Pulmonet 111 wet spirometer); maximal inspiratory and expiratory flow volume loop; total lung capacity (TLC) (Jaeger Body Plethysmograph); single-breath transfer factor of the lungs for carbon monoxide $(T \mathrm{~L}, \mathrm{CO})$ and gas transfer co-efficient $(K \mathrm{CO})(\mathrm{PK}$ Morgan transfer test). TL,CO values were corrected for haemoglobin. The definitions and methods for performing lung volumes and transfer factor followed the recommendations of the, European Coal and Steel Community $[10,11]$.

\section{Cardiac function}

Pulmonary artery pressure (PAP), pulmonary capillary wedge pressure (PCWP) and pulmonary vascular resistance (PVR) were collated from the preoperative assessment data. Postoperatively, PAP and PCWP were recorded at the time of right ventricular endomyocardial biopsy, taken at weekly intervals for 6 weeks and fortnightly for a further 6 weeks, and cardiac graft rejection was graded according to international classification [12].

\section{Virology}

Cytomegalovirus-specific immunoglobulin $\mathrm{G}$ and $\mathrm{M}$ ( $\mathrm{IgG}$ and $\operatorname{IgM}$ ) antibodies were measured by enzymelinked immunosorbent assay (ELISA) [13]. Patients and donors were screened for CMV-specific IgG prior to transplantation. Following transplantation, recipients were tested for CMV-specific IgG and IgM, and HCMV antigenaemia routinely at the same time as right ventricular biopsy. HCMV antigenaemia was tested for using a monoclonal antibody (mouse monoclonal antibody, Biosoft, TCS Biological Ltd, Boltolph, Claydon, Bucks, UK) against a $65 \mathrm{kDa}$ lower matrix phosphoprotein (pp65) within polymorphonuclear leucocytes [14]. Prospective surveillance data using HCMV antigenaemia was available on 23 of the heart transplant recipients. All patients received acyclovir, $200 \mathrm{mg}$ t.d.s., as prophylaxis against herpes simplex for 3 months following transplantation. CMV hyperimmunoglobulin was given as prophylaxis to HCMVseronegative recipients whose donors were seropositive, as detailed previously [15]. No other prophylaxis was administered to seropositive recipients during the study period.

\section{Definitions of cytomegalovirus infection}

It was considered that CMV infection was present at the time of a lung function test visit if: 1) there was current evidence of HCMV antigenaemia; 2) there was considered to be a clinical episode related to CMV (pyrexia of unknown origin, unexplained fall in white cell count) and this episode was subsequently followed by an $\operatorname{IgM}$ rise of greater than 4 units within 1 week of the lung function test visit; 3) there was an unexplained rise in CMV IgM (>4 units) coinciding with the lung function test visit; or 4) the $\operatorname{IgM}$ was raised in the presence of a clinical event considered to be related to CMV.

\section{Immunosuppression}

Immunosuppression was induced using azathioprine, $4 \mathrm{mg} \cdot \mathrm{kg}^{-1}$ preoperatively, and methylprednisolone 1 gram perioperatively. RATG $\left(1.5 \mathrm{mg} \cdot \mathrm{kg}^{-1}\right)$ was given on the first three postoperative days. Maintenance immunosuppression was achieved using a triple therapy regimen of cyclosporin $5 \mathrm{mg} \cdot \mathrm{kg}^{-1}$ daily, azathioprine $1-2 \mathrm{mg} \cdot \mathrm{kg}^{-1}$ daily, and prednisolone, $0.1-0.2 \mathrm{mg} \cdot \mathrm{kg}^{-1} \cdot$ daily.

\section{Cyclosporin}

Cyclosporin levels were routinely collected daily for the first 30 days following transplantation. Further samples were collected on each clinic visit every 2 weeks until 3 months following transplantation and then monthly until 6 months. Mean cyclosporin levels between lung function test visits and actual cyclosporin levels on the visit days were used in the analysis. Cyclosporin was measured by the enzyme multiplied immunoassay technique (EMIT) cyclosporin assay (CYVA Co., Palo Alto, CA, USA) and the dosage was adjusted to maintain the fasting whole blood concentration between 200-300 $\mu \mathrm{g} \cdot \mathrm{L}^{-1}$.

\section{Statistics}

Pre- and postoperative absolute and standardized residuals [16, 17] for lung function were compared using 
the paired Student's t-test. Standardized residual values for $\mathrm{KCO}$ were calculated from the study population $\mathrm{KCO}$ data. Pre- and postoperative haemoglobin were compared using the paired Student's t-test. A logarithmic transformation of bypass time was correlated with lung function by Pearsons correlation coefficient. Two-tailed probability and $95 \%$ confidence intervals were used. The relationship between lung function and grade of rejection, cyclosporin level, and PCWP was examined with Pearsons correlation coefficient at $30 \pm 10,60 \pm 10,90 \pm 10$, $120 \pm 10$ and $150 \pm 10$ days. Nonpaired Student's t-test was used to compare the lung function of those with CMV infection to those free of infection at 60 days. The TL,CO and $K \mathrm{CO}$ of those patients with CMV infection were compared to the $T \mathrm{~L}, \mathrm{CO} / K \mathrm{CO}$ when they were free of infection using a paired Student's t-test. All statistics were carried out on the Statistical Package for Social Services Software.

\section{Results}

\section{Cardiac and lung function prior to transplantation $(n=34)$}

The pretransplantation mean (and range) haemodynamic data were as follows: PAP $31(10-48) \mathrm{mmHg}$; PCWP 24 (6-40) mmHg; cardiac output 3.2 (2.6-5.6) L; PVR $1.6(1.1-3.4)$ Wood units $\left(\mathrm{mmHg} \cdot \mathrm{min} \cdot \mathrm{L}^{-1}\right)$; and pulmonary vascular resistance index (PVRI) 1.67 (1.6-7.1) Wood units $\cdot \mathrm{m}^{-2}$.

There was a negative correlation between the standardized residual value of plethysmographic TLC and both the PAP and PCWP ( $r=-0.36, p=0.04$; and $r=-0.34$, $\mathrm{p}=0.05$, respectively). There was no correlation with gas transfer measurements.

Lung function changes at the time of surgery (HTR versus $C A B G)$

The results detailing changes in absolute values are summarized in table 1 and the results detailing the changes in standardized residual values are summarized in table 2. At 30 days, both HTR and CABG patients had a significant fall in TLC and FVC, with no change in FRC or RV.

The haemoglobin $(\mathrm{Hb})$ concentration fell significantly in both groups postoperatively (HTR: pre-Hb, mean 13.7 $\mathrm{g} \cdot \mathrm{dL}-1$, post-Hb, mean $\left.11.7 \mathrm{~g} \cdot \mathrm{dL}^{-1}: \mathrm{p}=0.001\right)(\mathrm{CABG}$ : pre-Hb, mean $14.35 \mathrm{~g} \cdot \mathrm{dL}^{-1}$, post-Hb, mean $12.7 \mathrm{~g} \cdot \mathrm{dL}^{-1}$; $\mathrm{p}=0.001)$. The $T \mathrm{~L}, \mathrm{CO}$, corrected for changes in $\mathrm{Hb}$, fell significantly in both groups. In addition, the HTR had a significant fall in $\mathrm{KCO},(\mathrm{p}=0.006)$, which was not seen in the CABG patients $(\mathrm{p}=0.19)$. There was no relationship between change in gas transfer and the duration of cardiopulmonary bypass in either group.

\section{Lung function value at the late time-point (150 days) fol-} lowing cardiac transplantation

In the HTR there was no relationship at any time following transplantation between any lung function variable and concurrent rejection, or PCWP. The FEV1 of the HTR improved significantly at the late time-point (150 days) following transplantation, from mean \pm SEM $2.6 \pm 0.12 \mathrm{~L}$ to $2.9 \pm 0.6 \mathrm{~L}$ after 150 days, $\mathrm{p}=0.009$ (fig. 1a). The FEV1/VC ratio also improved from $77 \pm 1.7 \%$ to $82 \pm 1.4 \%, \mathrm{p}=0.001)$. However, at 150 days both the TL,CO (fig. 1b) and KCO (fig. 1c) remained significantly lower than before transplantation (absolute TL,CO from a mean of $6.7 \pm 0.4$ to $5.4 \pm 0.27 \mathrm{mmol} \cdot \mathrm{min}^{-1} \cdot \mathrm{kPa}^{-1}, \mathrm{p}=0.001$; absolute KCO from $1.4 \pm 0.1$ to $1.02 \pm 0.05 \mathrm{mmol} \cdot \mathrm{min}^{-1}$. $\mathrm{kPa}^{-1} \cdot \mathrm{L}^{-1}, \mathrm{p}=0.0001$; standardized residual $T \mathrm{~L}, \mathrm{CO}$ from a mean of $-2.4 \pm 0.2$ to $-3.2 \pm 0.1 \mathrm{mmol} \cdot \mathrm{min}^{-1} \cdot \mathrm{kPa}^{-1}, \mathrm{p}=0.001$; at 150 days post transplant). A positive correlation was seen between the standardized residual for $T \mathrm{~L}, \mathrm{CO}$, absolute $T \mathrm{~L}, \mathrm{CO}$ and the mean cyclosporin level at 150 days $(\mathrm{r}=0.48$, $\mathrm{p}=0.03$; and $\mathrm{r}=0.44, \mathrm{p}=0.049$, respectively). In addition, a positive correlation was seen between the absolute $K \mathrm{CO}$ and the actual $(r=0.56, p=0.019)$ and mean $(r=0.55$, $\mathrm{p}=0.012$ ) cyclosporin levels at 150 days.

The number of episodes of CMV infection were small and when spread across the visits, only at Visit 2 (60

Table 1. - Change in actual lung function variables at 30 days following surgery

\begin{tabular}{|c|c|c|c|c|c|c|}
\hline Lung function & $\begin{array}{l}\text { Before } \\
\text { surgery }\end{array}$ & $\begin{array}{l}\text { After } \\
\text { surgery }\end{array}$ & $\begin{array}{l}\text { Degree } \\
\text { of change }\end{array}$ & $\begin{array}{l}\text { Standard } \\
\text { error }\end{array}$ & $95 \% \mathrm{CI}$ & p-value \\
\hline \multicolumn{7}{|c|}{ Heart transplant recipients $(n=20)$} \\
\hline FEV1 L & 2.7 & 2.5 & -0.2 & 0.11 & -0.4 to 0.03 & 0.23 \\
\hline FVC L & 3.5 & 3.1 & -0.4 & 0.13 & -0.7 to -0.1 & 0.01 \\
\hline RV L & 1.9 & 1.9 & 0 & 0.1 & -0.2 to 0.2 & 0.68 \\
\hline FRC L & 3.0 & 2.8 & -0.2 & 0.5 & -1.2 to 0.8 & 0.11 \\
\hline TLC L & 5.5 & 5 & -0.5 & 0.2 & -0.9 to -0.1 & 0.02 \\
\hline$T \mathrm{~L}, \mathrm{CO} \quad \mathrm{mmol} \cdot \mathrm{min}^{-1} \cdot \mathrm{kPa}^{-1}$ & 6.5 & 5.5 & -1.0 & 0.3 & -1.6 to -0.4 & 0.002 \\
\hline KCO $\mathrm{mmol} \cdot \mathrm{min}^{-1} \cdot \mathrm{kPa}^{-1} \cdot \mathrm{L}^{-1}$ & 1.29 & 1.06 & -0.3 & 0.07 & -0.4 to -0.2 & 0.006 \\
\hline \multicolumn{7}{|l|}{ Control group $(n=14)$} \\
\hline FEV1 L & 3.2 & 2.5 & -0.7 & 0.31 & -1.4 to -0.03 & 0.0001 \\
\hline FVC L & 3.9 & 3.1 & -0.8 & 0.34 & -1.5 to -0.06 & 0.0001 \\
\hline RV L & 2.2 & 2.0 & -0.2 & 0.12 & -0.4 to 0.05 & 0.2 \\
\hline FRC L & 2.8 & 2.7 & -0.1 & 0.27 & -0.8 to 0.6 & 0.85 \\
\hline TLC L & 6.1 & 5.6 & -0.5 & 0.3 & -1.9 to $-0.6(-0.13)$ & 0.02 \\
\hline$T \mathrm{~L}, \mathrm{CO} \quad \mathrm{mmol} \cdot \mathrm{min}^{-1} \cdot \mathrm{kPa}^{-1}$ & 9.2 & 7.5 & -1.7 & 0.6 & -3.0 to -0.4 & 0.0002 \\
\hline KCO $\mathrm{mmol} \cdot \mathrm{min}^{-1} \cdot \mathrm{kPa}^{-1} \cdot \mathrm{L}^{-1}$ & 1.49 & 1.5 & 0.01 & 0.1 & -0.2 to 0.2 & 0.19 \\
\hline
\end{tabular}

Mean values for lung function values are presented. FEV1: forced expiratory volume in one second; FVC: forced vital capacity; RV: residual volume; FRC: forced residual capacity; TLC: total lung capacity; TL,CO: transfer factor of the lungs for carbon monoxide; KCO: carbon monoxide transfer coefficient; $95 \%$ CI: 95\% confidence interval. 
Table 2. - Change in standardized residual lung function values: at 30 days following surgery

\begin{tabular}{|c|c|c|c|c|c|c|}
\hline Lung function & $\begin{array}{l}\text { Before } \\
\text { surgery }\end{array}$ & $\begin{array}{c}\text { After } \\
\text { surgery }\end{array}$ & $\begin{array}{l}\text { Degree } \\
\text { of change }\end{array}$ & $\begin{array}{l}\text { Standard } \\
\text { error }\end{array}$ & $95 \% \mathrm{CI}$ & $\mathrm{p}$-value \\
\hline \multicolumn{7}{|c|}{ Heart transplant recipients $(\mathbf{n}=\mathbf{2 0})$} \\
\hline FEV1 $\mathrm{mL}$ & -1.7 & -1.9 & -0.2 & 0.2 & -0.6 to -0.1 & 0.231 \\
\hline FVC mL & -1.7 & -2.4 & -0.7 & 0.2 & -1.1 to -0.3 & 0.005 \\
\hline RV mL & -0.2 & -0.4 & -0.2 & 0.3 & -0.8 to 0.4 & 0.7 \\
\hline FRC mL & -0.5 & -0.8 & -0.3 & 0.2 & -0.7 to 0.1 & 0.107 \\
\hline TLC mL & -1.7 & -2.4 & -0.7 & 0.3 & -1.3 to -0.1 & 0.018 \\
\hline$T \mathrm{~L}, \mathrm{CO} \quad \mathrm{mmol} \cdot \mathrm{min}^{-1} \cdot \mathrm{kPa}^{-1}$ & -2.4 & -3.2 & -0.8 & 0.2 & -1.2 to -0.4 & 0.002 \\
\hline KCO $\mathrm{mmol} \cdot \mathrm{min}^{-1} \cdot \mathrm{kPa}^{-1} \cdot \mathrm{L}^{-1}$ & -1.55 & -3.72 & -2.18 & 0.72 & -3.69 to -0.67 & 0.007 \\
\hline \multicolumn{7}{|l|}{ Control group $(n=14)$} \\
\hline FEV1 $\mathrm{mL}$ & 0.2 & -2.9 & -2.7 & 1.4 & -6.1 to -0.1 & 0.006 \\
\hline FVC mL & -0.15 & -1.7 & -1.55 & 0.5 & -2.6 to -0.5 & 0.0001 \\
\hline $\mathrm{RV} \mathrm{mL}$ & 0.1 & -0.3 & -0.4 & 0.3 & -1.0 to 0.2 & 0.21 \\
\hline FRC $\mathrm{mL}$ & -0.5 & -1.1 & -0.6 & 0.5 & -1.6 to 0.48 & 0.053 \\
\hline TLC $\mathrm{mL}$ & 0.35 & -1.9 & -2.25 & 0.8 & -3.9 to -0.5 & 0.02 \\
\hline$T \mathrm{~L}, \mathrm{CO} \quad \mathrm{mmol} \cdot \mathrm{min}^{-1} \cdot \mathrm{kPa}^{-1}$ & -0.3 & -1.2 & -0.9 & 0.6 & -2.2 to 0.4 & 0.12 \\
\hline KCO $\mathrm{mmol} \cdot \mathrm{min}^{-1} \cdot \mathrm{kPa}^{-1} \cdot \mathrm{L}^{-1}$ & 0.63 & 0.05 & -0.58 & 0.50 & -1.66 to 0.50 & 0.26 \\
\hline
\end{tabular}

Mean standardized residual lung function values are presented. Negative value indicates less than the predicted value. For abbreviations see legend to figure 1 .
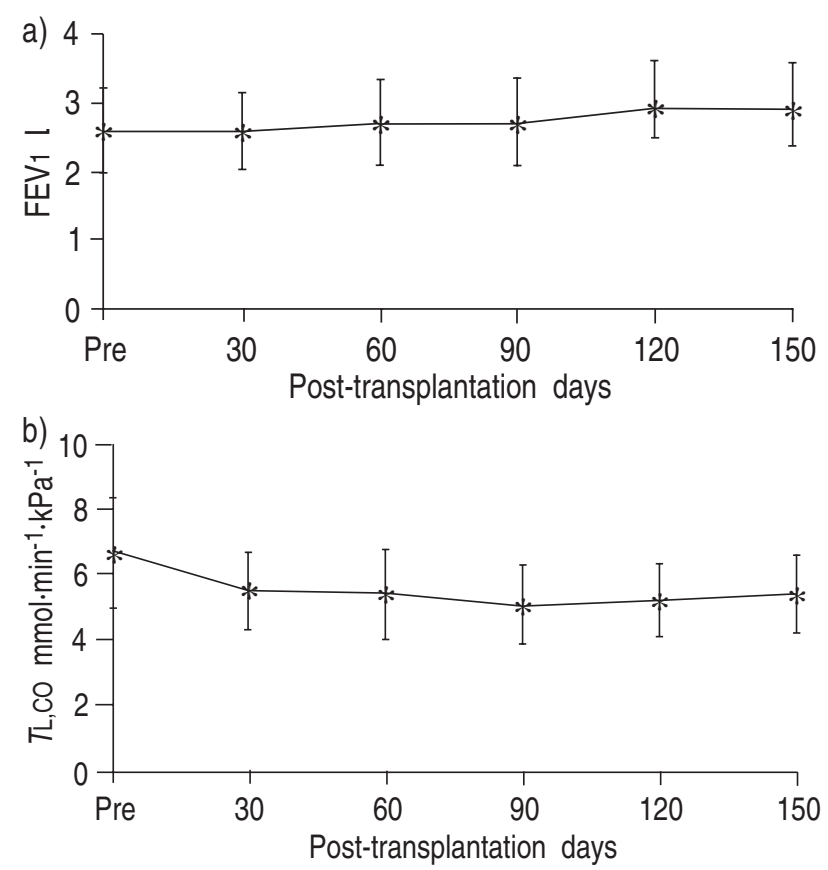

c)

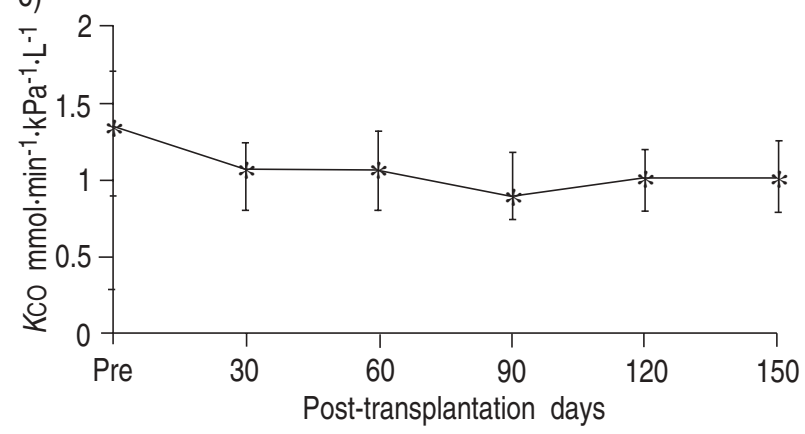

Fig. 1. - This shows the change in HTR a) forced expiratory volume in one second (FEV1); b) transfer factor of the lungs for carbon monoxide $(T \mathrm{~L}, \mathrm{CO})$ from before transplantation to 150 days following surgery; c) carbon monoxide transfer coefficient $(K \mathrm{CO})$, from before transplantation to 150 days following surgery. Values plotted as mean \pm 1 SD. HTR: heart transplant recipients; Pre: pretransplantation. days) were there sufficient patients $(n=6)$ with CMV infection at one time to allow a statistical comparison between patients with $\mathrm{CMV}$ infection and those free of CMV infection at that specific time-point. The presence of CMV infection was not found to influence either the standardized residual value or absolute value of $T \mathrm{~L}, \mathrm{CO}$ or KCO at 60 days following transplantation. Furthermore, no statistical difference existed between the mean TL,CO and the mean $K \mathrm{CO}$ for all the patients $(\mathrm{n}=11)$ who experienced $\mathrm{CMV}$ infection in comparison to the times when these same 11 patients were free of CMV infection.

\section{Discussion}

For this prospective study, absolute and standardized residual values for each of the lung function variables were analysed.

Standardized residual values were used in order to remove bias, which could occur by using percentage of predicted values $[16,17]$. This was particularly important because the age range of the patients studied varied from 16 to $60 \mathrm{yrs}$. In older patients, relatively lower values for percentage of predicted can be expected. As the prevalence of cytomegalovirus seropositivity occurs with greater frequency in older patients, an unfair bias may have occurred in the analysis by using percentage of predicted.

The effect of cardiac failure on lung function is controversial. Lung function studies prior to transplantation were completed immediately prior to cardiac haemodynamic measurement. The only relationship observed was a negative correlation between the standardized residual value of TLC and the PAP and PCWP. This finding suggests that changes in lung volumes closely reflect the influence of treated left heart failure on the lung. The diffusion impairment observed in up to one third of patients awaiting heart transplantation [9] was also documented in this group of patients (table 2). As there was no relationship between haemodynamic status and gas transfer, these changes may result from other factors, e.g. 
pulmonary embolism or drug toxicity [18]. Although both the FEV1 and FVC are proportionately reduced prior to transplantation (table 2), at the late time-point following transplantation the patients had a significantly improved FEV1, (fig. 1) and FEV1/VC ratio. This suggests that treated left heart failure additionally has an obstructive influence on the lung. Therefore, the physiological pattern of lung function in patients with treated heart failure awaiting heart transplantation includes a diffusion/restrictive defect and an obstructive defect, of which the former is most prominent.

Changes in lung function after transplantation could have been due to the operation itself. However, when the CABG group and the HTR were compared pre- and postoperatively both the absolute and standardized residual lung function values showed similar changes, with the exception of KCO. At 30 days postoperatively, both groups demonstrated a fall in TL,CO but when this was corrected for changes in alveolar volume, only the HTR demonstrated a significant fall in KCO. Both groups had reduced lung volumes (i.e. a significant fall in TLC and FVC with no change in FRC or RV), which are consistent with chest wall changes as a result of surgery [19], emphasizing the importance of a restrictive influence by the chest wall on pulmonary physiology $[20,21]$.

At the early time-point following surgery (30 days) the lung volume changes observed in the HTR were not as pronounced as in the CABG patients (tables 1 and 2). This may be explained by the fact that the HTR have an enlarged heart before surgery, resulting in lower lung volumes prior to transplantation. The reduction in heart size as a result of receiving a transplant, therefore, tended to minimize the restrictive changes induced by the sternotomy.

This prospective controlled study confirms that HTR have a fall in KCO by Day 30, persisting to Day 150. Some of the potential causes for the fall in the transfer coefficient after HT include bypass, changes in cardiac function, CMV infection [4], early immunosuppression (i.e. RATG/cyclosporin) and maintenance immunosuppression, especially cyclosporin [1,2]. Cardiopulmonary bypass might have resulted in microvascular/alveolar injury expressed as a fall in $\mathrm{KCO}$ but these changes were not seen in the CABG group nor was there any correlation between the change in $\mathrm{KCO}$ and the duration of bypass. Recent data suggest that lung injury occurring at the CABG is independent of bypass but dependent on other factors, such as stability of systemic pressure preoperatively and the requirement for blood transfusions [22].

The improvement in cardiac function following HT may influence the changes in gas transfer, with improved left atrial pressures abolishing an artificially elevated diffusion capacity prior to transplant, perhaps existing because of pulmonary vascular engorgement [23]. However, this seems unlikely for two reasons. Firstly, because of the lack of any relationship (pre- or postoperatively) between TL,CO and PCWP. Secondly, although the HTR experienced a fall in $\mathrm{Hb}$ concentration, a comparable change in $\mathrm{Hb}$ concentration was seen in the $\mathrm{CABG}$ patients. Despite the changes in $\mathrm{Hb}$ concentration, both groups had a significant fall in $\mathrm{TL}, \mathrm{CO}$, when corrected for $\mathrm{Hb}$.

Evidence which points to a new process occurring within the lungs of HTR is the contrasting changes in lung physiology following mitral valve repair. This study demonstrated a fall in gas transfer following HT and normalization of haemodynamics, whereas following mitral valve repair the lung physiology remains the same [24], or improves [25], despite persistently raised pulmonary artery pressures [24].

Events immediately following transplantation may have a role in the development of the physiological changes observed, but this study did not identify a definitive causal factor. In contrast to the control group, the induction of immunosuppression is a distinguishing characteristic of the HTR group. On the basis of the introduction of agents such as RATG, one might speculate on a possible immunological mechanism for the change in gas transfer. For instance, RATG has been shown to induce proinflammatory mediators, such as tumour necrosis factor- $\alpha$ (TNFa) [26] which itself is recognized as having specific effects on endothelial cells in the lungs [27]. TNF- $\alpha$ has also been reported to be a potentially important mediator in the development of adult respiratory distress syndrome [28].

Alternatively, as has been suggested before $[1,2]$ but remains unproven, the physiological changes could be caused by cyclosporin, which is introduced at the same time as RATG. Cyclosporin can affect the microvascular structure of the kidney causing nephrotoxicity, with two histological patterns, either an arteriolaropathy with narrowing of the vascular lumen or an interstitial fibrosis [29]. One might speculate that similar changes could occur at the microvascular/alveolar interface of the lung. Indeed, isolated pulmonary diffusion impairment has also been observed in renal transplant patients receiving cyclosporin [30]. A relationship between cyclosporin and a pulmonary microvascular injury is suggested by the positive statistical correlation between cyclosporin and transfer factor at 150 days following HT. Such a positive correlation could only be explained by the presence of alveolar haemorrhage. Large numbers of haemosiderin laden macrophages in the bronchoalveolar lavage (BAL) of HTR have been observed by ourselves (unpublished data) and others [31]. However, a statistical correlation cannot be taken as proof of a direct causal effect.

Previously, in a retrospective study, we have identified CMV infection as a risk factor for reduced transfer factor following heart transplantation [4]. In this prospective study, we were unable to confirm this relationship. Most importantly, we have demonstrated a fall in $K \mathrm{CO}$ which predates the time of CMV infection. There are a number of factors in the current study which have helped to define the lack of relationship with CMV. Firstly, standardized residuals were used rather than percentage of predicted. Secondly, more sensitive techniques were used for the diagnosis of CMV infection. Thirdly, strict chronological time-points were adhered to for the analysis of the interaction of CMV infection and lung function. However, the number of CMV infection episodes was low and this might have diluted any effect.

This prospective study has demonstrated that patients awaiting heart transplantation had a dominant diffusion/ restrictive defect in lung physiology. Heart transplant recipients then experienced a real fall in $K \mathrm{CO}$ and this seemed to be an early event following transplantation, implicating early immunosuppression. The diffusion 
impairment was persistent at the late time-point following transplantation but a relationship between $T \mathrm{~L}, \mathrm{CO} / K \mathrm{CO}$ and human cytomegalovirus infection was not demonstrated. A positive statistical correlation between $T \mathrm{~L}, \mathrm{CO} / K \mathrm{CO}$ and cyclosporin at the late time-point following heart transplantation suggests that cyclosporin may produce a low-grade pulmonary microvascular injury.

Acknowledgements: JJE is supported by the Lancardis Foundation. The authors wish to thank J. Morris for help with the statistical analysis and J. Feltham for secretarial assistance. The authors also wish to acknowledge the contribution of the "New Heart, New Start" appeal.

\section{References}

1. Casan P, Sarchis J, Cladellas M, Amergual MJ, Caral PS. Diffusing lung capacity and cyclosporin in patients with heart transplants. J Heart Transplant 1987; 6(1): $54-56$.

2. Groen HJ, Bogaard JM, Balk AH, Kho SG, Hop WC, Hilvering C. Diffusion capacity in heart transplant recipients. Chest 1992; 102: 456-460.

3. Ravenscraft SA, Gross CR, Kubo SH, et al. Pulmonary function after successful heart transplantation: one year follow-up. Chest 1993; 103: 54-58.

4. Egan JJ, Kalra S, Yonan N, Hasleton PS, Brooks N, Woodcock AA. Pulmonary diffusion abnormalities in heart transplant recipients: relationship to cytomegalovirus. Chest 1993; 104: 1085-1089.

5. Braun SR, Birnbaum ML, Chopra PS. Pre- and postoperative pulmonary function abnormalities in coronary artery revascularisation surgery. Chest 1978; 73(3): 316-320

6. Jorens PG, De Jongh R, De Backer W, et al. Interleukin8 production in patients undergoing cardiopulmonary bypass: the influence of pretreatment with methylprednisolone. Am Rev Respir Dis 1993; 148: 890-895.

7. Locke TJ, Griffiths TL, Mould H, Gibson GJ. Rib cage mechanics after median sternotomy. Thorax 1990; 45: 465-468

8. van Belle AF, Wesseling GJ, Penn OCKM, Wouters EFM. Postoperative pulmonary function abnormalities after coronary artery bypass surgery. Respir Med 1992; 86: 195-199.

9. Wright RS, Levine MS, Bellamy PE, Simmons MS, Batra $\mathrm{P}$, Warner Stevenson L. Ventilatory and diffusion abnormalities in potential heart transplant recipients. Chest 1990: 98; 816-820.

10. Quanjer PH, Tammeling GJ, Cotes JE, Pedersen OF, Peslin R, Yernault JC. Lung volumes and forced ventilatory flows. Eur Respir J 1993; 6 (Suppl. 16): 5-40.

11. Coates JE, Chinn DJ, Quanjer PH, Roca J, Yernault JC. Standardization of the measurement of transfer factor (diffusing capacity). Eur Respir J 1993; 6 (Suppl. 16): 41-52.

12. Billingham ME, Carey NRB, Hammond ME, et al. A working formulation for the standardization of nomenclature in the diagnosis of heart and lung rejection: heart rejection study group. J Heart Transplant 1990; 1: 587-593.
13. Morris DJ, Fox AJ, Grint PCA, Bell EJ, Lomax J, McCartney RA. Cytomegalovirus, varicella zoster and coxsackie B virus specific IgM antibody response in children with cancer. Serodiagn Immunother Infect Dis 1990; 4: 115-120.

14. Gerna G, Revello MG, Percivalle E, Morini F. Comparison of different immunostaining techniques and monoclonal antibodies to the lower matrix phosphoprotein (pp65) for optimal quantitation of human cytomegalovirus antigenemia. J Clin Microbiol 1992; 30: 1232-1237.

15. Freeman R, Gould FK, McMaster A. Management of cytomegalovirus antibody negative patients undergoing heart transplantation. J Clin Pathol 1990; 43: 373376.

16. Gibson GJ. Standardized lung function testing. Eur Respir J 1993; 6: 155-157.

17. Millar MR, Pincock AC. Predicted values: how should we use them? Thorax 1988; 43: 265-267.

18. Kuderchuk PJ, Pierson DJ, Greene HL, Graham EL, Sears GK, Trobrugh GB. Prospective evaluation of amiodarone pulmonary toxicity. Chest 1984 : 86: 541-548.

19. Derveaux L, Ivanoff I, Rochette F, Demedts M. Mechanisms of pulmonary function changes after surgical correction for funnel chest. Eur Respir J 1988; 1: 823-825.

20. Yernault JC, Gibson GJ. Interactions between lung and chest wall in restrictive ventilatory defects. Bull Eur Physiopathol Respir 1982; 18: 395-401.

21. Kenyon CM, Pedley TJ, Higenbottam TW. Adaptive modelling of the human rib cage in median sternotomy. J Appl Physiol 1991; 70(5): 2287-2302.

22. Louagie Y, Gonzalez E, Jamart J, Bulliard G, Schoevaerdts JC. Postcardiopulmonary bypass lung edema: a preventable complication? Chest 1993; 103: 86-95.

23. Ohar J, Osterloh J, Ahmed N, Miller L. Diffusing capacity decreases after heart transplantation. Chest 1993; 103: 859-861.

24. Ohno K, Nakahara K, Hirose H, Nahono S, Kawashima Y. Effects of valvular surgery on overall and regional lung function in patients with mitral stenosis. Chest 1987; 92(2): 224-228.

25. Rhodes KM, Evemy K, Nairman S, Gibson GJ. Effects of mitral valve surgery on static lung function and exercise performance. Thorax 1985; 40: 107-112.

26. Grant SCD, Lamb WR, Sallath $\mathrm{H}$, et al. Release of TNF-alpha, IL-6, and the TNF receptors p55 and p75 following RATG therapy in heart and heart/lung transplant recipients. J Heart Lung Transplant 1993; 12: 572.

27. Ward PA. Overview of the process of cellular injury in interstitial lung disease. Chest 1991; 100: 230-232.

28. Millar AB, Singer M, Meagher A, Foley NM, Johnson NMcI, Rook GAW. Tumour necrosis factor in bronchopulmonary secretions of patients with adult respiratory distress syndrome. Lancet 1989; ii: 712-714.

29. Kahan BD. Cyclosporin. N Engl Med J 1989; 321: 1725-1738.

30. Bush A, Gabriel R. Pulmonary function in chronic renal failure effects of dialysis and transplantation. Thorax 1991; 46: 424-428.

31. Grebski E, Hess T, Hold G, Speich R, Russi E. Diagnostic value of haemosiderin laden macrophages in bronchoalveolar lavage. Chest 1992; 102: 1794-1799. 